\title{
UM OLHAR DISCURSIVO SOBRE O TRABALHO, SUAS SIGNIFICAÇÕES E EFEITOS NO SOCIAL ${ }^{1}$
}

\author{
JULIANA DE CASTRO SANTANA ${ }^{2}$, RICARDO TADEU DE SOUZA ${ }^{3}$
}

Faculdade de Filosofia, Ciências e Letras Eugênio Pacelli

Programa de Pós-graduação em Ciências da Linguagem

Universidade do Vale do Sapucaí

Av. Pref. Tuany Toledo, 470 - 37550-000 - Pouso Alegre - MG - Brasil

julianacastrosantana@hotmail.com, ricardo tadeu souza@hotmail.com

\begin{abstract}
Resumo. Este estudo analisa os discursos do / sobre o trabalho que circulam na sociedade, considerando sua constituição histórica, ideológica e heterogênea nos processos de significação e de subjetivação. Lançaremos luz aos efeitos gerados pelas relações de trabalho que derivam da forma sujeito histórica capitalista neoliberal, de modo a contribuir para reflexões que levem em conta a linguagem na produção de sentidos e de práticas que afetam o social. Foram analisados dizeres que circulam na internet, a partir da afirmação inicial de Confúcio: "Escolha um trabalho que ame e não terás que trabalhar um único dia em sua vida". Os sentidos de trabalho em expressões como "ossos do oficio" e em definições dicionarizadas também foram historicizados, com base nos pressupostos da Análise de Discurso.
\end{abstract}

Palavras-chave: trabalho; subjetividade; sentidos; neoliberalismo.

\begin{abstract}
This study analyzes the discourses of / about work that circulate in society, considering its historical, ideological and heterogeneous constitution in the signification and subjectivation processes. We shed light on the effects generated by labor relations that derive from the neoliberal capitalist historical subject form, taking into account language in the production of meanings and practices that affect the society. Some sayings taken from the internet were analyzed, based on Confucius's initial statement: "Choose a job you love and you won't have to work a single day in your life". The different meanings of work in expressions such as "ossos do oficio" and dictionary definitions have also been historicized, considering the Discourse Analysis assumptions.
\end{abstract}

Keywords: work; subjectivity; meanings; neoliberalism.

\footnotetext{
${ }^{1}$ Este estudo divulga algumas das discussões propostas na pesquisa de mestrado desenvolvida por Ricardo Tadeu de Souza, sob orientação da Profa. Dra. Juliana de Castro Santana.

${ }^{2}$ Docente e pesquisadora no Programa de Pós-graduação em Ciências da Linguagem da UNIVAS.

${ }^{3}$ Mestre em Ciências da linguagem pela Universidade do Vale do Sapucaí.
} 


\section{INTRODUÇÃO}

As formas e os sentidos de trabalho têm passado por mudanças significativas, muito em função da revolução tecnológica, da produção do conhecimento cientificamente legitimado e das demandas sociais que criam novas maneiras de ofertar e consumir produtos e serviços para "nutrir" o capital. O objetivo deste estudo é analisar alguns dos sentidos de trabalho que circulam em nossa sociedade, sem perder de vista sua constituição histórica, ideológica e discursivamente heterogênea. Pretendemos lançar um olhar discursivo aos efeitos sociais e subjetivos gerados pelas relações laborais que culminam na atual forma sujeito histórica capitalista neoliberal, de modo a contribuir para reflexões que levem em conta a linguagem na produção de sentidos, de (des)identificações e de práticas discursivas que afetam o funcionamento da sociedade. Do ponto de vista teórico-metodológico, este estudo se ancora nos pressupostos da Análise de Discurso.

O discurso do trabalho como algo essencial para se obter o progresso já se fez memória e habita o imaginário social. Pela perspectiva discursiva, interessa-nos analisar como os sentidos de trabalho e de práticas laborais foram se constituindo ao longo da história e se associando - praticamente numa relação de causa e efeito - a outros significantes como progresso, cidadania, dignidade, desenvolvimento econômico, consumo, dentre outros. A princípio, pareceu-nos significativo historicizar os sentidos socialmente compartilhados de trabalho, com base na origem epistemológica deste vocábulo e de alguns significados que foram dicionarizados.

Ao adentrarmos a espessura histórica do vocábulo trabalho podemos observar sua constituição polissêmica e o modo como os sentidos foram se constituindo e se deslocando. A origem etimológica ${ }^{4}$ desta palavra provém do latim tripalium, termo formado pela conexão dos elementos tri, cujo significado é "três", e palum, "madeira": uma ferramenta de tortura formada por três estacas afiadas de madeira, muito comum na Europa antiga, utilizada para flagelar os escravos e aqueles que não conseguiam pagar os impostos. Ironicamente, naquele tempo, as pessoas que não tinham posses eram as que trabalhavam e tinham a obrigação de produzir, ou seja, o trabalho árduo era realizado pelos desafortunados e socioeconomicamente desfavorecidos.

Atualmente, o discurso em circulação sobre o trabalho ganhou uma roupagem meritocrática, ao preconizar que aqueles que não têm posses, bens materiais e condições financeiras favoráveis não se esforçaram o suficiente ou não trabalharam duro o bastante e são, portanto, preguiçosos, relapsos, desinteressados e não merecem a recompensa de ter acesso a oportunidades e bens de consumo que só os "verdadeiros" trabalhadores conseguem obter. Esses dizeres são construídos por meio de práticas sociais, culturais, políticas e econômicas e, principalmente, pela tônica do capitalismo e da necessidade de ampliação da produção.

Com base no latim, o termo tripalium deslizou para travailler, em língua francesa, que também remete, inicialmente, à definição de "sentir dor" ou "sofrer" e, com o passar das décadas, a palavra foi sendo empregada para se referir a "uma atividade exaustiva ou atividade difícil, dura". Foi somente no século XIV que a palavra trabalho e suas três

4 Dicionário Etimológico: etimologia e origem das palavras, 2008 - 2019. Disponível em https://www.dicionarioetimologico.com.br. Acesso em 08/08/2019. 
poderosas sílabas começaram a ter o sentido que lhe é atribuído nos dias de hoje, que se relaciona à "aplicação das forças e faculdades (talentos, habilidades) humanas para alcançar determinado fim". A palavra trabalho carrega, em si, um efeito polissêmico e muitas significações. Como exemplo, podemos mencionar o dicionário online Michaelis ${ }^{5}$, que apresenta 23 definições distintas para o verbete trabalho, incluindo definições teóricas e não consensuais advindas de diferentes campos do saber: da Sociologia, Antropologia, História, Psicologia, etc.

\section{trabalho}

\section{tra.batho}

$\mathrm{sm}$

1 Conjunto de atividades produtivas ou intelectuais exercidas pelo homem para gerar uma utilidade e alcançar determinado fim: Ele sempre se dedicou ao trabalho académico.

2 Atividade profissional, regular, remunerada ou assalariada, objeto de um contrato trabalhista: Conseguiu seu primeiro trabalho quando tinha 18 anos.

3 O exercicio dessa atividade: 0 trabalho de um professor é muito mal remunerado.

4 Local onde se exerce essa atividade: Saiu para o trabalho muito cedo.

5 Qualquer obra (manual, artistica, intelectual) realizada; empreendimento, realizaçào: Seu trabalho à frente do coral é fantástico.

6 A feitura ou execuçăo de uma obra; lavor: O trabalho que ele executa na pedra-sabăo é belissimo.

7 Aço ou maneira de executar uma tarefa, de utilizar um instrumento: Seu trabalho com nanquim é perfoito.

8 Tarefa a ser cumprida; servico: 'A Bruxa, indiferente, năo interrompera sequer o seu trabalho; ao passo que a das Dores, de máos nas cadeiras [...], um cigarro no canto da boca, encarava desdenhosa a sanha daquele marido [... I (AA1).

9 Esmero ou cuidado empregado na feitura de uma obra ou de um servico: Teve muito trabalho para entregar a reforma da casa com um alto padrắo de qualidade.

10 Qualquer tarefa que è ou se tornou uma obrigaçao ou responsabilidade de alguém; dever, encargo: Meu trabalho passou a ser a coordenaçăo das tarefas dos monitores que participariam do congresso.

11 Tarefa escolar com prazo de entrega predeterminado, feita individualmente ou um grupo, geralmente fora do estabelecimento de ensino, envolvendo pesquisa e maior reflexào: Ainda năo consegui terminar o trabalho de histónia.

Figura 1. Significados da palavra trabalho no dicionário3.

\footnotetext{
${ }^{3}$ Dicionário Michaelis. Editora Melhoramentos, 2019. Disponível em https://michaelis.uol.com.br/. Acesso em 10/08/2019.
} 
12 Conjunto de exercicios objetivando desenvolvimento $\theta$ aprimoramento fisico, artistico, intelectual etc.: O preparador físico já definiu o trabalho que fara com os jogadores.

13 Esforç incomum; faina, lida, luta: "Achava que estava ficando velho, sb lhe nasciam filhas com todas as mulheres, a vida se tornava cada vez mais dificil e entåo queria passar uns dias descansando, sem o trabalho pesado da caça" (JU).

14 Açào exercida por elemento natural de forma progressiva e continua $e 0$ efeito dessa açăo sobre o meio.

15 Resultado útil da açăo e do funcionamento de um aparelho, de um maquinismo etc: 0 trabalho do trator é indispensável para a movimentação de terra e cascalhos na construção de estradas.

16 fich Conjunto de fenômenos que ocorrem em determinada matéria, produzindo alteraça de sua natureza e forma.

17 Movimento produzido nos materiais industriais.

18 ECON. POUT Atividade humana caracterizada como fator principal da produção de bens ou serviços.

19 Flos No marxismo, atividade de transformação do trabalhador que, além de tirar da natureza os bens necessários para sua subsistência, usa sua força produtiva para criar uma nova ordem social, politica e econômica com a emancipação do proletariado e a socializaçăo dos meios de produçâo.

20 Fis Grandeza escalar obtida do produto dos vetores força e deslocamento do seu ponto de aplicaça, cuja unidade de medida no SI é o joule; é uma forma de transferir energia.

21 REL Em cultos afro-brasileiros, principalmente na umbanda e na quimbanda, rituais realizados para alcançar objetivos de proteçào e auxilio ou de maleficios e prejuizo a alguém: Pediu a sua măe de santo que fizesse um trabalho para ele conseguir um emprego.

22 PEs Execugalo de um delito: O trabalho do intermediário do bicheiro era negociar o valor da aprovação das licitaçס̃es superfaturadas.

23 coloQ Qualquer roubo ou assalto: Aqui estāo as joias, chefe. O trabalho foi executado com sucesso.

(continuação) Figura 1. Significados da palavra trabalho no dicionário.

Sob as atuais condições de produção, o termo emprego ganhou um efeito metafórico ${ }^{6} \mathrm{e}$ passou a fazer parte das práticas discursivas sobre o trabalho. Este deslizamento pode ser percebido etimologicamente ${ }^{7}$, pois a palavra emprego vem do latim implicare, que significa "juntar", "unir" ou "entrelaçar", termo formado a partir do prefixo in e do morfema plicare, que significa "enrolar ou dobrar" (como uma folha de papel). Diante

\footnotetext{
${ }^{4}$ A noção de deslize e efeito metafórico situa a questão do funcionamento na relação do discurso com a língua. M. Pêcheux (1969) vai chamar de efeito metafórico o fenômeno semântico produzido por uma substituição contextual, lembrando que esses deslizamentos de sentido entre x e y é constitutivo do sentido designado por $\mathrm{x}$ e por $\mathrm{y}$. Como esse efeito é característico das línguas naturais, por oposição aos códigos e às línguas artificiais, podemos considerar que não há sentido sem essa possibilidade de deslize e, pois, sem interpretação. $\mathrm{O}$ que nos leva a colocar a interpretação como constitutiva da própria língua (natural) (ORLANDI, 2015, p.31).

5 Dicionário Etimológico: etimologia e origem das palavras, 2008 - 2019. Disponível em https://www.dicionarioetimologico.com.br. Acesso em 10/08/2019.
} 
disso, implicare definia-se pelo ato de envolver alguém em determinada situação ou ato e, diacronicamente, este vocábulo passou pelos seguintes estágios de grafia na Língua Portuguesa: enplegar, enpregar, enpregare, até chegar em empregar.

Conceder emprego ou empregar alguém também significa manter alguma relação de envolvimento fixo, contínuo ou periódico, baseado em um ponto de interesse em comum: o trabalho e seu produto ou produção. Observa-se que a paráfrase e a polissemia são eixos que constituem os sentidos das palavras "emprego" e "trabalho", produzindo, na atualidade, um efeito de sinonímia ou de quase indistinção entre esses termos. Sobre as noções de paráfrase e de polissemia que constituem os processos discursivos e de significação, Nogueira (2015), retomando os estudos de Orlandi, afirma que

a paráfrase e a polissemia são dois eixos que constituem o funcionamento da linguagem e o movimento permanente da produção da significação por meio da repetição e da diferença e é aí que podemos tratar da dispersão e da incompletude, pensando a relação de sentidos. (NOGUEIRA, 2015, p. 42)

Nesse prisma, se retomarmos os significados de trabalho como uma forma de tortura (tripalium) e sofrimento (travailler), não atrelados somente à ação de açoitar outrem, mas também às extenuantes atividades físicas realizadas pelos trabalhadores, podemos afirmar que, salvo as devidas proporções, esses sentidos ainda estão presentes na atual forma sujeito histórica neoliberal e no modo de nos relacionarmos com o trabalho.

$\mathrm{Na}$ sequência, abordaremos alguns dizeres que circulam em nossa sociedade sobre o trabalho, de modo a vislumbrarmos alguns efeitos sociais e subjetivos das práticas laborais na contemporaneidade.

\section{“OSSOS” OU “ÓCIOS” DO OFÍCIO?}

Em sua materialidade linguística, a palavra trabalho estabelece uma relação com suplício, calvário, dissabor e esses sentidos se repetem e se deslocam nas práticas discursivas cotidianas, inclusive através dos ditados populares. Estes ditados, geralmente constituídos de frases curtas, carregam um dizer sucinto sobre algo, sem uma origem ou autoria definida e ganham circulação no meio social, produzindo identificações e efeitos de verdade. Sobre a natureza dos provérbios, Lysandro-Dias (2001) afirma que

[...] Os provérbios têm dualidades, ou seja, apesar de já estarem cristalizados, são flexíveis e se adaptam a temas atuais. São um elemento familiar e, ao mesmo tempo, trazem novidade e estranhamento porque rompem com o fio do discurso. (LYSANDRODIAS, 2001, online)

Ao percorrermos alguns ditados relacionados ao trabalho, deparamo-nos com frases utilizadas recorrentemente, que reforçam e naturalizam a dificultosa, penosa e dura vinculação do homem com o labor, tais como: "Deus ajuda quem cedo madruga", "o preguiçoso trabalha dobrado", "amigos, amigos, negócios à parte", "em casa de ferreiro o espeto é de pau", "filho criado trabalho dobrado" etc. 
Diante de dizeres que ainda se fazem presentes, gostaríamos de chamar a atenção para um em específico: a expressão "ossos do ofício", que parece brincar com a língua, valendo-se da polissemia para produzir significação. Uma das mais populares definições do verbete "ofício"8 está atrelada à realização de algum esforço para o qual alguém é capacitado, especializado e apto. A palavra "ossos", além de sua definição científica relacionada à anatomia, como parte rígida e estruturante da composição do corpo humano e animal, ganha sentidos outros, produzindo um efeito sinonímico de dificuldade, empecilho ou obstáculo, "a parte mais difícil de roer" ou "osso duro de roer", como se diz popularmente.

A expressão "ossos do ofício" costuma ser empregada para expressar e descrever ocasiões, situações ou acontecimentos em que um profissional precisa executar atos ou tarefas pelos quais não têm apreço. É possível observar o jogo discursivo acontecendo nesta expressão: há uma fal(h)a na língua que produz sentidos outros, ao estabelecer um vínculo entre o ofício e o sacrifício. Este funcionamento só ganha significação porque está atrelado à história, ao funcionamento da ideologia e da memória discursiva que interpela o sujeito em trabalhador. São sentidos produzidos historicamente, que conferem a este dizer um efeito polissêmico, "um deslocamento, ruptura de processos de significação. [...] joga com o equívoco" (ORLANDI, 2015, p. 34).

Ao longo de nossa pesquisa, nos deparamos com variações desta mesma expressão e conjecturas sobre o seu possível surgimento, que se mostraram significativas sob o ponto de vista discursivo. Encontramos, no Dicionário inFormal ${ }^{9}$, a variação do referido ditado para "ócios do ofício", que, independentemente da época de seu surgimento, aponta para um deslize, para a movimentação da própria língua e de sua formulação. Ao confrontarmos as duas versões, o efeito metafórico é percebido no deslocamento da palavra "ócios" para "ossos" (ou de "ossos" para "ócios"), preservando elementos fonéticos que produzem um efeito de homofonia, alterando sutilmente a estrutura gramatical e impactando radicalmente a produção de sentidos, uma vez que eles "poderiam ser os mesmos, no entanto escorregam, derivam para outros sentidos, para outras posições. A deriva, o deslize é o efeito metafórico, a transferência, a palavra que fala com outras" (ORLANDI, 2015, p. 50). Ao relacionarmos "ócios" com "ossos" a contradição aparece; há um furo, uma fuga dos sentidos, já que o "ócio" está associado ao tempo livre, descanso, a um momento prazeroso, enquanto o sentido produzido pela palavra "ossos" nos remete à fadiga, cansaço. Para além de sua estrutura morfológica, observamos que ossos e ócios funcionam e significam como antítese, pois, ao mesmo tempo que causam um mecanismo de antecipação ${ }^{10}$ dos sentidos, conduzem os interlocutores a gestos de interpretação distintos.

Como um último gesto de leitura da expressão em destaque, trazemos para a reflexão elementos encontrados no dicionário eletrônico Significados $\mathrm{BR}^{11}$, que busca uma

\footnotetext{
${ }^{8}$ Dicionário Michaelis. Editora Melhoramentos, 2019. Disponível em https://michaelis.uol.com.br/. Acesso em 31/08/2019.

9 Dicionário inFormal, 2006-2019. Disponível em https://www.dicionarioinformal.com.br/. Acesso em $31 / 08 / 2019$

${ }^{10}$ Eni Orlandi (2015, p. 37), retomando os estudos de Pêcheux, conceitua o mecanismo de antecipação como a capacidade que todo sujeito tem de se colocar no lugar em que o seu interlocutor "ouve" suas palavras. Antecipando-se, assim, a seu interlocutor quanto ao sentido que suas palavras produzem.

${ }^{11}$ Significados BR: o que significa (significados), conceitos e definições ao seu alcance, 2019. Disponível em https://www.significadosbr.com.br/ossos-do-oficio. Acesso em 31/08/2019.
} 
possível origem deste ditado popular. De acordo com este dicionário, a expressão emerge do processo produtivo de branqueamento da folha de papel com tutano; papel este com medidas e gramaturas específicas, conhecido também como ofício. O pó de tutano é uma substância encontrada no interior dos ossos e, decênios atrás, era utilizado como alvejante, responsável por dar o aspecto alvo às folhas de papel. Como este processo de clareamento era extremamente trabalhoso, lento e possuía uma simbologia negativa, ancorou-se o termo "ossos do ofício" às atividades que exigissem esforço ou grande dificuldade em sua execução. É uma origem instigante, mas o surpreendente é que, mesmo em diferentes condições de produção e com distintos sentidos atribuídos às materialidades "ofício" e "ossos", a expressão ganha significação não por conta da folha ou do tutano, mas por causa do dificultoso trabalho executado durante o processo de branqueamento da folha, pela experiência em si de empreender um grande esforço para realizar uma tarefa ou atividade. Historicizando este dito popular, são notórios os deslizamentos e efeitos de sentido produzidos por ele, graças ao funcionamento da ideologia, do interdiscurso e da memória discursiva; fenômenos que são da instância do inconsciente e se dão pelo esquecimento (ORLANDI, 2015).

\section{SENTIDOS SOBRE O TRABALHO EM DIZERES SOCIALMENTE COMPARTILHADOS}

Ao analisarmos as discursividades e os sentidos que são produzidos a partir da definição de trabalho do século XIV e da noção de tortura atrelada ao labor, podemos observar que, na atualidade, estes sentidos também deslizaram e passaram a significar não só os desgastes corpóreos, mas também os desgastes psíquicos, sendo o trabalho a causa mortis de cerca de 120.000 pessoas por ano (somente nos Estados Unidos), em função de transtornos mentais e doenças como a síndrome de burnout (termo criado para definir quem se exaure de trabalhar), depressão e ansiedade. Esses dados, expostos pela pesquisa de Jeffrey Pfeffer ${ }^{12}$, compõem um triste retrato social. Mortes ocasionadas por rotinas altamente estressantes, excesso de horas de atividade, cobranças por produção e agilidade, pressão e precarização das formas de trabalho são comuns no neoliberalismo. Os números da Previdência Social do Brasil mostram que o nosso país também sofre deste mal: houve um crescimento de $12 \%$ (comparado a 2017) no número das licenças concedidas pelo INSS por transtornos mentais e comportamentais adquiridos no trabalho, superando 8.000 licenças formais concedidas nos primeiros nove meses do ano 2018.

Trouxemos, anteriormente, a noção de deslize e efeito metafórico, pois "o modo de conceber o deslize, o efeito metafórico como constitutivo do funcionamento discursivo, liga-se ao modo de conceber a ideologia, discursivamente [...] e isso nos aponta para o discurso duplo e uno" (ORLANDI, 2015, p. 20 apud PÊCHEUX, 1975). Essa noção nos permite entrever o jogo discursivo em funcionamento no mercado de trabalho e nas significações que o trabalho produz na atualidade. Apesar de os dados numéricos mostrarem, em várias pesquisas, que o sofrimento relacionado ao trabalho tem tomado proporções gigantescas, o discurso posto em circulação parece produzir efeitos de sentido distintos dessa realidade social, incentivando que a população trabalhe cada vez mais e se esforce para atingir a felicidade pelo sucesso profissional que, por sua vez, aparece vinculado à ascensão social. Discursos de autoempreendedorismo, motivação, superação,

12 Você RH, Ed. fev./mar. 2019. Matéria Causa Mortis: trabalho. São Paulo: Ed. Abril, 2019. 
reconhecimento, autonomia, poder e tantos outros aparecem aos montes no mercado de trabalho mundial; frases formuladas por grandes nomes e de alto impacto social são massificadas e transpostas de um cenário a outro, sem a devida problematização, produzindo o efeito de que o trabalho é a melhor e a única saída para todos. Tem-se, assim, uma interpretação já dada sobre o trabalho, como se nenhuma outra fosse possível. Em outras palavras, há um saber discursivo sobre o trabalho, sócio-historicamente construído e compartilhado, que retorna sob a forma de pré-construído, produzindo um efeito de verdade sobre a função do trabalho em nossa sociedade.

A famosa afirmação de Confúcio "Escolha um trabalho que ame e não terás que trabalhar um único dia em sua vida" e o provérbio japonês "Treine enquanto eles dormem, estude enquanto eles se divertem, persista enquanto eles descansam, e então, viva o que eles sonham" são exemplos de enunciados cujos sentidos se (re)atualizam na sociedade contemporânea, ratificando a importância do trabalho para a vida e para as conquistas pessoais. A recompensa, o progresso e uma vida supostamente melhor tornam-se as mais importantes promessas a serem alcançadas através do trabalho.

É interessante observar que a afirmação de Confúcio só significa porque evoca sentidos que relacionam o trabalho a algo que, necessariamente, não se ama, que traz sofrimento. Então, é preciso buscar o prazer de alguma forma nas práticas laborais. O pensador chinês projeta toda a responsabilidade da realização profissional no sujeito trabalhador, ao passo que, fazer o que se ama, o blindará das mazelas e o protegerá de todo o "mal" que pode ser ocasionado pelo labor. Em contrapartida, fazer aquilo que não se ama ressoa como consequência de uma escolha equivocada, realizada pelo próprio sujeito trabalhador. Não pretendemos ser incrédulos diante das possibilidades de satisfação e autorrealização que o trabalho é capaz de proporcionar; no entanto, nos parece bastante questionável a conexão estabelecida entre trabalho e amor, apenas pela ótica passional e romantizada, segundo a qual felizes são aqueles que fazem o que lhes proporciona prazer. A nosso ver, trata-se de uma prescrição idealizada de felicidade, uma vez que poucos têm a possibilidade de escolher o trabalho que desejam e, mesmo aqueles que o escolhem, trabalham em ambientes profissionais diversos, cercados de relações interpessoais, sociais, culturais e políticas conflituosas, que produzem algum tipo de mal-estar, mesmo diante daquilo que, a princípio, se tem grande apreço.

A afirmação de Confúcio tende a produzir identificações, angariando adeptos para a força de trabalho, mas, ao sairmos de sua superficialidade ou do efeito de evidência, notamos se tratar de um dizer cujos sentidos podem ser outros, pois está sujeito à equivocidade da língua posta em funcionamento sob determinadas condições de produção. A fim de explorarmos alguns dos sentidos que derivam da afirmação inicial de Confúcio, trazemos, abaixo, algumas postagens retiradas da internet que atualizam os sentidos deste enunciado, no formato de paródias. 


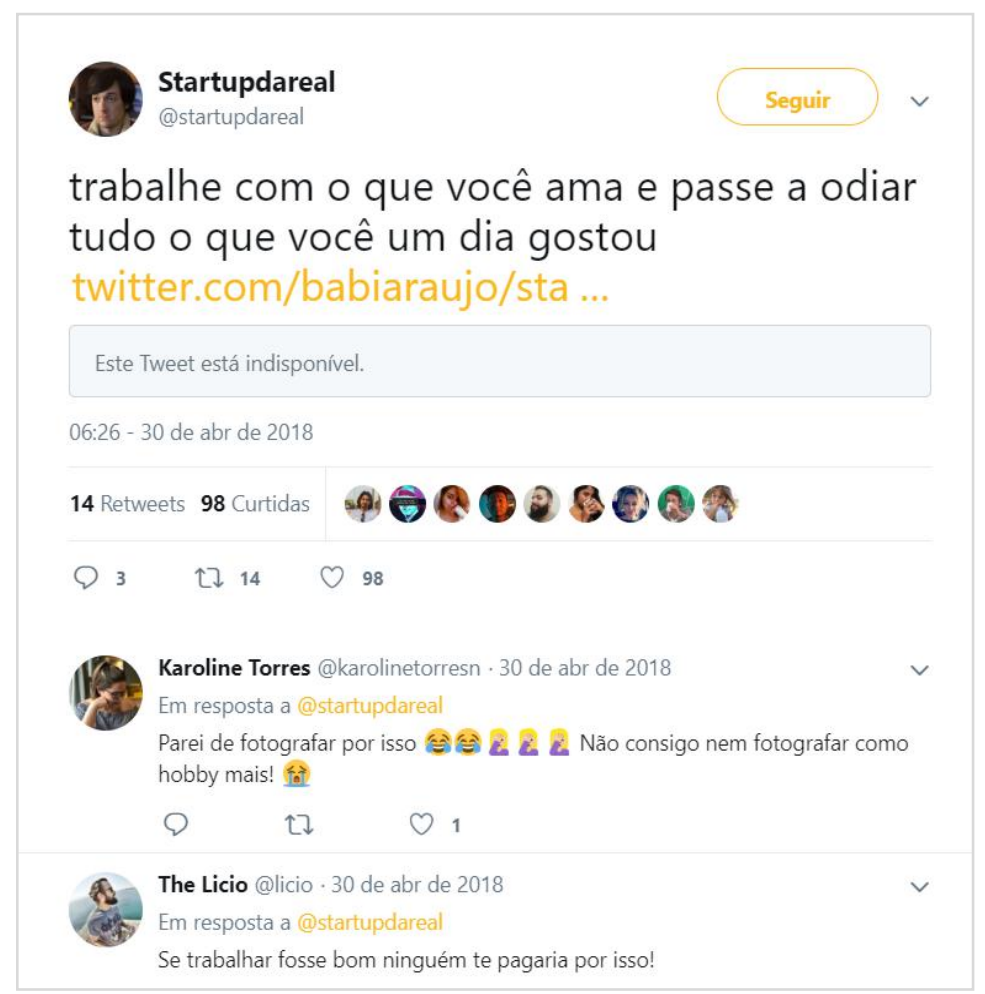

Figura 2. Postagem de um usuário no Twitter. Fonte: @startupdareal, Twitter, 2018³.

É possível observarmos as noções de intertextualidade e de interdiscurso funcionando e produzindo novos sentidos nas postagens acima, fazendo com que os dizeres sobre o trabalho se redefinam e signifiquem, na relação da língua com a história. Para entender a paródia contida no post é necessário, antes de tudo, ter o conhecimento e resgatar, intertextualmente, os dizeres iniciais de Confúcio que possibilitam a antecipação dos sentidos, bem como o deslize, que abre espaço para novos gestos de interpretação e de significação. É nesta relação que o intertexto e o interdiscurso parecem funcionar, evocando o enunciado primeiro e produzindo sentidos outros, sob determinadas condições de produção.

Estamos considerando as postagens no Twitter como uma atualização da célebre frase, pois a forma como o trabalho é significado atualmente se modificou em diversos aspectos. Confúcio $^{14}$ viveu na Idade Média oriental, cerca de 500 anos antes de Cristo, em uma época desprovida de tecnologias de plantio e com necessidade de fortalecimento da agricultura. Como mencionado anteriormente, as práticas trabalhistas ainda eram baseadas na servidão, deixando poucas opções aos explorados, senão trabalhar duro para seu sustento e de sua família. Naqueles tempos, alguns filósofos faziam parte da nobreza, pela sua intelectualidade e influência social; outros sofriam perseguição, dependendo do quão controversas suas ideias soavam para o Estado. Confúcio se destacava por seu brilhantismo, característica que lhe atribuiu o título do pai do Confucionismo, um código

${ }^{13}$ STARTUPDAREAL. Trabalhe com o que você ama e passe a odiar tudo o que um dia você gostou. Via Twitter:@startupdareal. Publicado em 30/04/2018, 06:26. Disponível em https://witter.com/startup dareal/status/990945391133720576. Acesso em 20/08/2019.

${ }^{14}$ SGARIONI, Mariana. As lições do Mestre. Superinteressante [digital]. Publicado em 21/12/2004, 22:00.

Disponível em https://super.abril.com.br/historia/as-licoes-do-mestre/. Acesso em 25/09/2019. 
filosófico-político, com normas e comportamentos sociais baseados na ética e no humanismo, que beira a religião e é seguido fortemente por empresas ocidentais e orientais na atualidade, que parecem desconhecer as condições em que o dizer de Confúcio foi produzido.

Quando Confúcio disse, na Idade Média, para fazer o que se ama, ao que, de fato, ele se referia? A quem era direcionado este dizer, tendo em vista que os servos deveriam continuar as atividades de sua família? Seria essa uma prerrogativa para abreviar o sofrimento da força de trabalho explorada ou para alimentar as esperanças e aumentar a produtividade em corpos cansados?

Descrever as condições em que o enunciado de Confúcio foi primeiramente proferido se faz necessário, pois, desde os tempos do filósofo até a atualidade, as práticas discursivas sobre o trabalho passaram a produzir sentidos outros. Também os sujeitos passaram a se inscrever e a se identificar com estas práticas laborais de formas distintas, atribuindo ao ato de trabalhar muito mais do que um ganha-pão, tornando-o, além de fonte de subsistência, um ponto de convergência com o consumo, com o status e com a base de sua constituição subjetiva.

O animal laborans pós-moderno não abandona sua individualidade ou seu ego para entregar-se pelo trabalho a um processo de vida anônimo da espécie. A sociedade laboral individualizou-se numa sociedade de desempenho e numa sociedade ativa. O animal laborans pós-moderno é provido do ego ao ponto de quase dilacerar-se. Ele pode ser tudo, menos ser passivo. (HAN, 2017, p. 43)

Mesmo que grandes empresas e lideranças tenham incorporado a frase de Confúcio para motivar seus empregados e seguidores, colocando o amor ao trabalho como condição para o sucesso e produtividade, as condições sócio-históricas que sustentaram a produção do enunciado inicial de Confúcio são outras na atualidade, fazendo com que a relação do homem com o trabalho apareça, hoje, associada ao amor e não mais ao sofrimento. Ao pressupor que é prazeroso trabalhar com o que se ama, coloca-se o trabalho como eixo central da vida em sociedade: um pilar constituinte da felicidade e do sucesso. $\mathrm{Na}$ postagem reproduzida acima, ao evocar o enunciado de Confúcio e produzir uma paródia a partir dele, assumindo a função autor, outro gesto de interpretação se produz pelo atravessamento do interdiscurso, pelas atuais condições de produção e pela filiação a determinadas formações discursivas.

Quando nos referimos ao autor como função, estamos nos ancorando na noção postulada por Orlandi (2015). Nas palavras da referida autora,

ao nosso ver, a função autor é tocada de modo particular pela história: o autor consegue formular, no interior do formulável, e se constituir, com seu enunciado, numa história de formulações. O que significa que, embora ele se constitua pela repetição, esta é parte da história e não mero exercício mnemônico. Ou seja, o autor, embora não instaure discursividade (como o autor original de Foucault) produz, no entanto, um lugar de interpretação no meio de outros. (ORLANDI, 2015, p. 27) 
Quando formula "trabalhe com o que ama e passe a odiar tudo o que um dia gostou", o autor da postagem cria um efeito contraditório que traz em sua textualidade uma série de práticas e de maneiras de se relacionar com o trabalho que estão se tornando naturalizadas na atualidade. Uma dessas práticas é a repetição incessante da mesma função, a fim de se alcançar a perfeição, exigindo do empregado muito esforço e horas intermináveis dedicadas à mesma atividade (motora ou intelectual). Outra prática bastante propagada é a da produtividade que está presente nos discursos corporativos e faz parte de qualquer organização, pública ou privada. Já não basta o trabalhador ser muito bom na tarefa que realiza, é preciso produzir cada vez mais, elevar os níveis de rendimento, ser proativo e gerar, como consequência, excelentes resultados, que vão aumentando, de tempos em tempos, obrigando-o a produzir ainda mais e a pensar em formas mais eficientes de realizar as mesmas atribuições, de preferência em tempo recorde. Junta-se a isso as pressões que o mercado impõe em termos de prazos, qualidade, redução de gastos, concorrência, postura profissional, controle emocional, cumprimento de metas para se obter o bônus e tantas outras. $\mathrm{O}$ amor que se tinha por realizar um trabalho acaba sendo abafado em meio a tantas exigências, produzindo ansiedade e desprazer.

Observa-se, na postagem acima, a utilização dos antônimos amor e ódio como um jogo de linguagem que nos remete ao que Pêcheux [1969] (GADET; HAK, 2014, p. 73) define como "campo semântico", que é essa escolha das palavras que visam "coerções" semânticas entre os campos morfemáticos em uma área de significação dada, criando, neste caso, efeitos de interpretação opostos, em que o trabalho é capaz de transformar a afeição em aversão, deixando entrever certas condições sócio-históricas que transformam o que era amor em ódio. Retomando o referido autor,

[...] pode-se dizer que a normalidade local que controla a produção de um tipo de discurso dado concerne não somente à natureza dos predicados que são atribuídos a um sujeito, mas também às transformações que esses predicados sofrem no fio do discurso e que o conduzem a seu fim nos dois sentidos da palavra. (PÊCHEUX [1969] em GADET; HAK, 2014, p. 73)

No enunciado "trabalhe com o que ama e passe a odiar tudo o que um dia gostou", a transformação de uma determinada atividade em trabalho se torna a raiz do problema, colocando, no centro do dilema, não a função, atividade ou hobby desempenhados, ou mesmo o processo em si do saber-fazer, mas o desafeto com aquilo que se torna institucionalmente uma ocupação. Ao ser atravessada pela ideologia e evocar a memória do dizer, a postagem em questão nos permite vislumbrar que o amor se torna ódio, a partir do momento em que algum ofício se qualifica socialmente como trabalho. Tal processo de significação se dá numa relação de oposição e contradição com a afirmação inicial de Confúcio.

A identificação produzida pela postagem acima pode ser percebida nos comentários que a seguiram, nos quais outros internautas corroboram a percepção do autor e reforçam seu posicionamento, afirmando: "Parei de fotografar, não consigo nem fotografar como hobby mais" e "Se trabalhar fosse bom, ninguém te pagaria por isso". A institucionalização do saber-fazer como profissão pode mudar o sentimento do trabalhador em relação a algo que ele costumava gostar, talvez por tornar a prática tão desgastante e obtusa que o sujeito não consegue mais encontrar nada de prazeroso naquela atividade. Os gestos de leitura e interpretação mobilizados, com base nesses textos, vão 
ao encontro da ideia de que o trabalho precisa ser duro, que o dinheiro justo não vem fácil e fazer aquilo que se ama pode ser uma armadilha. Quando o usuário reforça "se trabalhar fosse bom", ele filia-se a uma formação discursiva em que o trabalho representa, necessariamente, algo ruim. Ao empregar o verbo "ir" no pretérito imperfeito do subjuntivo, sua formulação frasal expressa um desejo distante, não concluído, de que o trabalho fosse algo bom. Logo, diante de tanto desprazer, a exclusiva recompensa é o dinheiro: única moeda de troca pela qual vale tolerar tamanhos abusos, pois é no poder econômico que se instalam as possibilidades de prazer e fuga das consequências e síndromes geradas por este ciclo vicioso de cansaço.

A Consolidação das leis do trabalho ${ }^{15}$ brasileiras oficializa a relação entre empregador e empregado, estabelecendo regras e cargas horárias de trabalho de até 44 horas semanais, com folgas aos sábados e domingos. Existem diversas outras modalidades de ocupação como os horistas, mensalistas e autônomos, mas, para fins ilustrativos, nos limitaremos ao formato mais recorrente de "segunda a sexta", já que, graças a ele, originaram-se duas expressões que reforçam a proximidade entre o trabalho e os sintomas de mal-estar. A primeira delas é a chamada "Síndrome da segunda-feira", que não é classificada oficialmente pelo Ministério da Saúde ${ }^{16}$ ou $\mathrm{OMS}^{17}$ (Organização Mundial da Saúde), mas é popularmente conhecida pela sensação de desânimo, letargia e desconforto que acomete os trabalhadores quando as segundas-feiras se aproximam, anunciando o início de mais uma semana de trabalho. Outra expressão bem difundida é "Síndrome do Fantástico", que produz um sentido próximo ao da "Síndrome da segunda-feira", fazendo referência ao horário noturno em que começa o programa dominical Fantástico, exibido pela Rede Globo de televisão, há duas gerações, indicando que o início da semana está próximo, inclusive por sua música, que ficou marcada na memória, tornando-se motivo de melancolia e incômodo.

O que ambas expressões parecem materializar é a forma como a nossa rotina é estruturada, com base na centralidade do trabalho como organizador das práticas sociais: com responsabilidades e trabalho durante a semana e lazer quase que exclusivamente aos finais de semana. Essas práticas nos dizem muito sobre a inquietação instalada na população brasileira. O incômodo é tanto que existem dicas ${ }^{18}$ de como driblar a "Síndrome de segunda-feira" / "Síndrome do Fantástico", antes de iniciar mais uma jornada semanal de trabalho.

\footnotetext{
${ }^{15}$ Consolidação das leis do trabalho - CLT e normas correlatas. Brasília: Senado Federal, Coordenação de Edições Técnicas, 2017. Disponível em http://www2.senado.leg.br/bdsf/bitstream/handle/id/535468 /clt e normas correlatas 1ed.pdf. Acesso em 08/08/2019.

${ }^{16}$ O Ministério da Saúde é o órgão do Poder Executivo Federal responsável pela organização e elaboração de planos e políticas públicas voltados para a promoção, a prevenção e a assistência à saúde dos brasileiros.

${ }^{17}$ Agência especializada em saúde, que teve sua fundação em 1948 e está alinhada à Organização das Nações Unidas. Consta em sua constituição que a OMS tem por objetivo desenvolver ao máximo o nível de saúde de todos os povos. A saúde sendo definida nesse mesmo documento como um "estado de completo bem-estar físico, mental e social e não consistindo somente da ausência de uma doença ou enfermidade". Disponível em https://www.who.int/eportuguese/countries/bra/pt/. Acesso em 08/11/2019. ${ }^{18}$ FERNANDEZ, Adriana. Como driblar a síndrome de segunda-feira? Exame [Portal digital]. Publicado em 27/07/2015, 11:05. Disponível em https://exame.abril.com.br/estilo-de-vida/saiba-o-que-fazer-paradriblar-a-sindrome-da-segunda-feira/. Acesso em 10/10/2019.
} 


\section{escolha um trabalho que vc ame e nunca terá que trabalhar}

\section{porque nao tem vaga}

Figura 3. Postagem de um usuário no Twitter. Fonte: @crltttnl via @MemesDopl3, Twitter. ${ }^{19}$

Esta outra paródia, construída a partir dos dizeres de Confúcio, nos remete ao igual e ao diferente, pois, ao mesmo tempo que retoma, intertextualmente, o que foi dito pelo filósofo, também o transforma em outro, atribuindo-lhe novas e diferentes significações, que repousam sob condições de produção específicas do Brasil e sua acentuada crise econômica, que perdura desde 2015. Devido à situação do país, as taxas de desemprego atingiram níveis alarmantes, com um percentual de desocupação de $12,7 \%$ da força de trabalho ${ }^{20}$. A falsa sensação de segurança discursivizada pelo meio corporativo passou a ser ameaçada, gerando instabilidade emocional ao trabalhador e alimentando uma atmosfera social de medo e insegurança.

Alguns gestos de leitura nos chamam a atenção na referida postagem: primeiro, a produção de efeitos de sentido que remetem ao fato de que não são todas as pessoas que podem escolher um trabalho, apesar de o dizer inicial ser constituído de um verbo imperativo que soa como prescrição e possibilidade (escolha!); segundo, caso o sujeito trabalhador só aceite fazer o que ama, corre o risco de ficar sem emprego, uma vez que a oferta de mão-de-obra é grande e não há vagas suficientes para todos, especialmente se houver uma seleção criteriosa para exercer determinada atividade, fazendo valer a expressão que circula popularmente "se tu não quer, tem quem queira"; terceiro, as tecnologias estão avançando e substituindo algumas das atividades que costumavam ser exercidas por humanos, deixando as oportunidades e alguns postos de trabalho cada vez mais restritos. Nestes três gestos de leitura e interpretação da postagem acima, observase a presença do interdiscurso e da memória discursiva que faz despontar um dizer não dito, mas que segue produzindo significações. Com base em Orlandi (2015, p. 24), que retoma o conceito de memória discursiva proposto por Pêcheux, podemos compreender que a afirmação acima traz à tona dizeres anteriores, já falados em outros lugares, independentemente - sobre a política brasileira, a pobreza, a violência, a falta de educação, o fracasso associado ao desemprego - que apontam para condições sócio-

${ }^{19}$ CRLTTTN via MEMESDOPL3. Escolha um trabalho que você ame e nunca terá que trabalhar, porque não tem vaga. Ano (?). Via Twitter: @crltttn. Disponível em https://pt.dopl3r.com/memes/810149/. Acesso em 07/10/2019.

${ }^{20}$ Dados da Pesquisa Nacional por Amostra de Domicílios Contínua (Pnad Contínua), realizada pelo Instituto Brasileiro de Geografia e Estatística (IBGE) no primeiro trimestre de 2019. Disponível em https://www.ibge.gov.br/estatisticas/sociais/trabalho/9171-pesquisa-nacional-por-amostra-de-domicilioscontinua-mensal.html? edicao $=24663 \& \mathrm{t}=$ destaques. Acesso em 14/08/2019. 
históricas que costumam ser apagadas ou esquecidas nos dizeres sobre o trabalho, mas que são de suma importância para compreensão da organização social a partir do trabalho e da constituição do sujeito de direitos e deveres.

\section{QUESTIONAR PARA NÃO CONCLUIR...}

Partindo dos dizeres que circulam em nossa sociedade sobre o trabalho e das reflexões aqui arroladas, podemos propor alguns questionamentos que não encerram nem concluem esta discussão, mas que podem ser significados diferentemente para produzir deslocamentos: Será que existe alguma liberdade ou possibilidade de escolha do trabalho que de fato se ama? Que tipo de trabalhador o Mercado quer? Qua(is) profiss(ões) o Mercado precisa e demanda que o sujeito ame? Mesmo que se tenha acesso ao emprego dos sonhos, seria possível mantê-lo de forma prazerosa, levando-se em conta as metas que se deve atingir em tempo recorde? É presumível que não.

Com base em Orlandi (2015, p. 37), que associa as relações de força ao discurso autoritário, podemos concluir que o Mercado (no caso deste estudo, o Mercado de Trabalho) se sobrepõe à figura do Estado, direcionando suas políticas e individuando o sujeito trabalhador para que se adapte às novas regras e demandas ditas sociais e de todos. Essa força do discurso mercadológico é tão presente na atual forma sujeito histórica capitalista neoliberal que ganhou centralidade no funcionamento da sociedade que se organiza no/pelo trabalho. Apesar dos furos e resistências, somos ideologicamente interpelados pela ideologia hegemônica do sistema no qual estamos inseridos. As instituições, ao propagar discursos sobre criar legados, pensar "fora da caixa", fazer o que se acredita, ter um olhar único e especial para a atividade exercida no trabalho, produzem um efeito de liberdade e de criatividade que cativa adeptos e entusiastas. No entanto, são as práticas e demandas impostas pelo Mercado que regulam o que o trabalhador deve ou não amar e não o contrário.

A associação do trabalho ao progresso faz parte de uma lógica vociferada pelo Mercado e pelo Estado neoliberal que vem aplacando não somente o indivíduo (aqui falando empiricamente), mas também a coletividade, produzindo consequências destrutivas em países como o Japão que, no período pós-guerra, precisou estimular a população a trabalhar de modo desenfreado para reconstruir o país e hoje colhe os frutos dessa busca desmedida pelo progresso. Segundo matéria veiculada no jornal BBC News Brasil ${ }^{21}$, o país registra, desde a década de 60 , casos de Karoshi, que se caracteriza pela morte por excesso de trabalho, causada especialmente por doenças cardíacas e mentais associadas diretamente ao exagero de horas dedicadas ao trabalho. Essas consequências sociais emergem do funcionamento das práticas discursivas atreladas ao corpo do sujeito e ao político. Foucault (2009) aborda o fenômeno de "sistemas punitivos concretos", trazendo contribuições relevantes para pensarmos a relação entre o corpo, o político, as relações de poder e a produção. Nas palavras do autor:

Mas o corpo também está diretamente mergulhado num campo político; as relações de poder têm alcance imediato sobre ele; elas o investem, o marcam, o dirigem, o supliciam, sujeitam-no a trabalhos, obrigam-no a

${ }^{21}$ BBC News Brasil [Jornal eletrônico], 2018. Disponível em https://www.bbc.com/portuguese/interna cional-45253773. Acesso em 10/08/2019. 
cerimônias, exigem-lhe sinais. Este investimento político do corpo está ligado, segundo relações complexas e recíprocas, à sua utilização econômica; é, numa boa proporção, como força de produção que o corpo é investido por relações de poder e de dominação; mas em compensação sua constituição como força de trabalho só é possível se ele está preso num sistema de sujeição (onde a necessidade é também um instrumento político cuidadosamente organizado, calculado e utilizado); o corpo só se torna força útil se é ao mesmo tempo corpo produtivo e corpo submisso. (FOUCAULT, 2009, p. 22)

O assujeitamento ao modelo de Mercado, que se apodera dos corpos como força de trabalho, nos individuando em sujeito trabalhador, parece ser inevitável, pois nos organizamos em uma sociedade na qual o trabalho exerce uma posição central, produzindo identificações com dizeres quase inquestionáveis do tipo: "é o trabalho que dignifica o homem". São discursividades como essas, institucionalizadas pelo Estado e suas políticas, que passam a produzir um efeito de verdade e de evidência, dentro de um sistema regido por práticas neoliberais que pregam a máxima produção e a competitividade. A crítica de Foucault (2009) ao contratualismo parte do fato de o ser já nascer como um sujeito de direitos e deveres, só que são contratos fantasiosos, já que não há o indivíduo, tampouco direitos. Na obra "Vigiar e punir" (FOUCAULT, 2009), o referido autor ressalta que a vigilância das instituições está tão presente no social que se torna inquestionável na interioridade do homem. Determinados comportamentos e práticas sociais ganham efeito de "verdades absolutas" e o próprio homem se incube de vigiar-se e punir-se por fazer algo diferente do prescrito. Nesse prisma, é comum que o sujeito trabalhador vigie o seu tempo, a fim de se manter produtivo, mesmo nas horas destinadas ao lazer ou ao descanso remunerado. Institui-se, nas/pelas práticas sociais, que é o trabalho que deve ser remunerado e não o descanso.

Historicamente, a palavra trabalho produz efeitos de sentido que não são fixos à palavra e que nos remetem a diferentes significações, dependendo das condições sócio-históricas de enunciação. Observa-se, atualmente, uma íntima relação do trabalho com o sofrimento e o mal-estar. Nota-se que o significante trabalho nos remete a outros significantes e não se mantém preso a apenas um significado.

Perguntamo-nos, por fim: o trabalho, suas práticas e sentidos atrelados ao sofrimento e à tortura se transformaram ao longo da história ou somente ganharam novas roupagens até chegarem à atual conjuntura histórica neoliberal? "Trabalho" é um tema que não morre, mas produz sentidos de sofrimento e morte através dos séculos.

\section{REFERÊNCIAS}

CONSOLIDAÇÃO DAS LEIS DO TRABALHO - CLT e normas correlatas. Brasília: Senado Federal, Coordenação de Edições Técnicas, 2017. Disponível em http://www2.senado.leg.br/bdsf/bitstream/handle/id/535468/clt_e normas_correlatas_1ed.pdf.

Acesso em 08/08/2019.

DICIONÁRIO ETIMOLÓGICO: etimologia e origem das palavras, 2008-2019. Disponível em https://www.dicionarioetimologico.com.br/. Acesso em 08/08/2019.

DICIONÁRIO INFORMAL. Disponível em https://www.dicionarioinformal.com.br/.

DICIONÁRIO MICHAELIS. Editora Melhoramentos, 2019. Disponível em https://michaelis.uol.com.br/. Acesso em 10/08/2019. 
FERNANDEZ, A. Como driblar a síndrome de segunda-feira? Exame [Portal digital], 27/07/2015. Disponível em https://exame.abril.com.br/estilo-de-vida/saiba-o-que-fazer-paradriblar-a-sindrome-da-segunda-feira/. Acesso em 10/10/2019.

FOUCAULT, M. Vigiar e punir: nascimento da prisão. 36ª ed. Petrópolis: Vozes, 2009.

GADET, F.; HAK, T. (Orgs.). Por uma análise automática do discurso: uma introdução à obra de Michel Pêcheux. $5^{\text {a }}$ ed. Campinas: Editora da Unicamp, 2014.

HAN, Byung-Chul. Sociedade do cansaço. Rio de Janeiro: Editora Vozes, 2017.

INSTITUTO BRASILEIRO DE GEOGRAFIA E ESTATÍSTICA (IBGE). Pesquisa Nacional por Amostra de Domicílios Contínua (Pnad Contínua): divulgação trimestral, 2019. Disponível em https://www.ibge.gov.br/estatisticas/sociais/trabalho/9171-pesquisa-nacional-por-amostrade-domicilios-continuamensal.html?edicao $=24663 \& \mathrm{t}=$ destaques. Acesso em 14/08/2019.

LYSANDRO-DIAS, Dylia. Provérbios que são notícia: uma análise discursiva. Boletim UFMG, Belo Horizonte, ano 27, n. 1316, p. 4, 2001. Disponível em https://www.ufmg.br/boletim/bol1316/quarta.shtml. Acesso em 30/08/2019.

MINISTÉRIO DA SAÚDE, 2013-2019. Disponível em http://saude.gov.br/.

NOGUEIRA, L. Discurso, sujeito e relações de trabalho: a posição discursiva da Petrobrás. Tese. Doutorado em Linguística, Universidade Estadual de Campinas, Instituto de Estudos da Linguagem, Campinas, SP, 2015.

ORLANDI, E.P. Análise de Discurso: princípios e procedimentos. Campinas: Pontes, 2015.

ORLANDI, E.P. Análise de discurso. Em: ORLANDI, E.P.; LAGAZZI-RODRIGUES, S. (Orgs.). Introdução às Ciências da Linguagem: discurso e textualidade. $3^{\mathrm{a}}$ ed. Campinas: Pontes, 2015. p. 13-36.

ORLANDI, E.P. O estatuto do texto na história da relação sobre a linguagem. Em: Discurso e texto: formulação e circulação dos sentidos. Campinas: Pontes, 2001. p. 73-98.

ORGANIZAÇÃO MUNDIAL DA SAÚDE, 2019. Disponível em https://www.who.int/eportuguese/countries/bra/pt/. Acesso em 08/11/2019.

VOCÊ RH, Ed. fev./mar. 2019. Matéria Causa Mortis: trabalho. São Paulo: Editora Abril, 2019.

SIGNIFICADOS BR: o que significa (significados), conceitos e definições ao seu alcance, 2019. Disponível em https://www.significadosbr.com.br/ossos-do-oficio. Acesso em 31/08/2019.

SGARIONI, M. As lições do Mestre. Superinteressante [digital]. 21/12/2004. Disponível em https://super.abril.com.br/historia/as-licoes-do-mestre/. Acesso em 25/09/2019.

UCHOA, P. Por que o Japão está pedindo que os trabalhadores tirem uma manhã de segundafeira de folga. BBC News Brasil [Jornal eletrônico], 21/08/2018. Disponível em https://www.bbc.com/portuguese/internacional-45253773. Acesso em 10/08/2019.

Artigo recebido em: out. de 2019.

Aprovado e revisado em: nov. de 2019.

Publicado em: dezembro de 2019.

Para citar este texto:

SANTANA, Juliana de Castro; SOUZA, Ricardo Tadeu de. Um olhar discursivo sobre o trabalho, suas significações e efeitos no social. Entremeios [Revista de Estudos do Discurso, ISSN 21793514, on-line, www.entremeios.inf.br], Seção Estudos, Programa de Pós-Graduação em Ciências da Linguagem (PPGCL), Universidade do Vale do Sapucaí (UNIVÁS), Pouso Alegre (MG), vol. 20, Especial, Dossiê "Língua, discurso e trabalho na contemporaneidade", p. 29-44, dez. 2019. DOI: http://dx.doi.org/10.20337/ISSN2179-3514revistaENTREMEIOSvol20pagina29a44 